\title{
Computationally Identifying Novel NF-кB-Regulated Immune Genes in the Human Genome
}

\author{
Rongxiang Liu, Richard C. McEachin, and David J. States ${ }^{1}$ \\ Bioinformatics Program and the Department of Human Genetics, University of Michigan, Ann Arbor, Michigan 48109, USA
}

\begin{abstract}
Identifying novel NF-KB-regulated immune genes in the human genome is important to our understanding of immune mechanisms and immune diseases. We fit logistic regression models to the promoters of 62 known $\mathrm{NF}$-кB-regulated immune genes, to find patterns of transcription factor binding in the promoters of genes with known immune function. Using these patterns, we scanned the promoters of additional genes to find matches to the patterns, selected those with NF- $\mathrm{B}$ binding sites conserved in the mouse or fly, and then confirmed them as NF-кB-regulated immune genes based on expression data. Among 6440 previously identified promoters in the human genome, we found 28 predicted immune gene promoters, 19 of which regulate genes with known function, allowing us to calculate specificity of $93 \%-100 \%$ for the method. We calculated sensitivity of $42 \%$ when searching the 62 known immune gene promoters. We found nine novel NF-kB-regulated immune genes which are consistent with available SAGE data. Our method of predicting gene function, based on characteristic patterns of transcription factor binding, evolutionary conservation, and expression studies, would be applicable to finding genes with other functions.
\end{abstract}

The human immune system is our host defense system against microbes and environmental hazards, and thus understanding immune mechanisms is of great interest in medical and biological research. NF-кB is a transcription factor (TF) that is known to be an important mediator of immune responses (Baeuerle and Baltimore 1996; Ghosh et al. 1998), and the 62 known NF-кB-regulated immune genes play fundamental roles in both innate immunity and adaptive immunity. A draft of the human genome sequence was published recently (International Human Genome Sequencing Consortium 2001; Venter et al. 2001), and it is estimated that there are about 35,000 genes in the human genome. More than half of these genes are novel, and it is reasonable to hypothesize that some of these novel genes have immune functions. Because of the importance of NF-кB signaling in the immune system, identifying these novel NF-кB-regulated immune genes will advance our understanding of human immunity and immune diseases.

Gene promoters are regulatory regions that are integral components of genes. For the purposes of this study, a promoter is the regulatory region of the gene that is proximal to the transcription start site (TSS). Eric Davidson used the patterns of TF binding sites in the promoters of sea urchin developmental genes to build a computational model to accurately predict their expression (Yuh et al. 1998). In Drosophila, TF binding-site patterns in regulatory regions have been used to search the fly genome to find developmental genes (Berman et al. 2002; Markstein et al. 2002). In mammals, efforts using logistic regression analysis (LRA) models of regulatory regions to find muscle and liver genes have also seen some success (Wasserman and Fickett 1998; Krivan and Wasserman 2001).

\section{'Corresponding author.}

E-MAIL dstates@umich.edu; FAX (734) 615-6553.

Article and publication are at http://www.genome.org/cgi/doi/10.1101/ gr.911803. Article published online before print in March 2003.
For most genes in the human genome, the precise locations of TSSs and their proximal promoters are still unknown. As such, finding the promoters is often a necessary first step in studying gene regulation, and previous work in our lab has involved finding these sites (Liu et al. 2001; Liu and States 2002). For genes with known mRNAs, our prediction method, CONPRO, has been shown to identify promoters with $70 \%$ sensitivity and over $90 \%$ specificity. Applying CONPRO to the human genome, we found 6440 promoters for genes with known mRNAs.

To identify novel NF-кB-regulated immune gene promoters among these 6440 promoters, we used the patterns of TF binding sites in the promoters of known NF-кB-regulated immune genes and evolutionary conservation of the NF-кB binding sites, then confirmed the predictions based on available expression data. We retrieved 62 known NF-кB-regulated immune response genes and their promoters (Baeuerle and Baichwal 1997), and we found that five TF families (including NF-кB) have binding sites overrepresented by a factor of at least two in these immune gene promoters. This overrepresentation suggests that these TFs are important in coregulating immune genes. We fit two LRA models, based on the patterns of binding sites for these five TFs and the positions of the NF- $\mathrm{kB}$ binding site within these promoters, then searched the 6440 promoters to find preliminary candidates for immune gene promoters. To improve the specificity of our predictions, these preliminary candidates were checked for NF-кB binding-site conservation between the human and mouse genome, or the human and Drosophila genome when mouse genomic data were not available. Serial analysis of gene expression (SAGE) data on myeloid, lymphoid, and microvascular endothelial cells are consistent with nine of these genes being activated by NF- $\mathrm{kB}$ in vivo, and we identified them as putative novel NF-кB-regulated immune response genes. Our method has sensitivity of $42 \%$, and our two LRA models show specificity of $93 \%$ and $100 \%$, respectively. 


\section{RESULTS}

\section{Positions of NF-кB Binding Sites in Immune Gene Promoters}

We first looked for positional preferences in the NF-кB binding sites of 62 known NF-кB-regulated mammalian immune gene promoters (Baeuerle and Baichwal 1997). In Figure 1, the cumulative percentage of NF-кB binding sites in these 62 promoters is plotted against the position relative to the TSS (solid curve, Fig. 1). For reference, among a set of mammalian nonimmune promoters, NF-кB binding sites appear as random noise without positional preference (dotted curve, Fig. 1). Among immune genes, the region immediately upstream of the TSS contains the highest density of NF-кB sites, whereas the region further upstream also contains an enrichment of NF- $\mathrm{kB}$ sites relative to nonimmune promoters, but not as high as in the proximal region. To find the breakpoint between these two regions, we used piecewise linear regression (S-Plus 6.0 ) to find the turning point in the curve at $-230 \mathrm{bp}$ (solid lines, Fig. 1). Over $75 \%$ of NF-кB binding sites in the immune gene promoters are within $230 \mathrm{bp}$ upstream of the TSS, and NF- $\kappa \mathrm{B}$ binding is more significant in these genes than in immune genes with the NF- $\mathrm{B}$ binding site farther upstream. We built separate LRA models for these two groups of genes.

\section{Informative Transcription Factors in NF-кB-Regulated Immune Promoters}

Regulation of eukaryotic gene expression is normally the consequence of interactions among a network of TFs (Kadonaga 1998; Lemon and Tjian 2000), and thus, in addition to NF- $\mathrm{BB}$, binding sites for other TFs may be informative in identifying immune genes. We searched for these other informative TFs in NF-кB-regulated immune gene promoters by looking for TFs with binding sites that are overrepresented in NF-кBregulated immune gene promoters. To find overrepresented TF binding sites, we compared the number of promoters with at least one binding site for a TF between two groups of promoters: the group of 62 known immune gene promoters and a null group that includes four sets of 62 mammalian nonimmune promoters taken from the Eukaryotic Promoter Database (EPD; Perier et al. 2000). Evaluating all TFs in the TRANSFAC database (Wingender et al. 2000), we selected those with binding sites that are at least twice as frequent in the NF-кB-regulated group as in the null group. The TFs that meet this criterion are AP1, IK1, IK3, IRF1, IRF2, ISRE, NF-кB, and STAT (Fig. 2, left). For comparison, the number of promoters containing binding sites for eight other TFs (Fig. 2, right) is not significantly different between immune and nonimmune promoters. This result is consistent with biological observations, because NF- $\mathrm{BB}$ has been shown to interact with AP1 and IRF1 to regulate genes (Thanos and Maniatis 1995), and the other five overrepresented TFs also have documented roles in the immune system. We grouped these TFs into five families by binding site sequence similarity: IK1 and IK3 are combined into IK, whereas IRF1, IRF2, and ISRE are combined into IRF, leaving informative TFs: NF-кB, AP1, IK, IRF, and STAT.

\section{Logistic Regression Models}

We used logistic regression to model the probability that a given promoter fits into the group of immune promoters, versus the group of nonimmune promoters, given the pattern of informative TF binding sites in the promoter. Based on our earlier observation that there are proximal and distal regions in the 62 known immune gene promoters, representing different levels of NF- $\kappa B$ regulation, we built one LRA model for immune promoters with NF- $\kappa \mathrm{B}$ binding sites within $230 \mathrm{bp}$ upstream of the TSS (Table 1, left) and one model for promoters with more distal NF-кB binding sites (Table 1, right). For both models, the most informative TF is NF- $\mathrm{B}$, which is expected for NF-кB-regulated immune genes, but the presence or absence of the other informative TF binding sites also helps categorize promoters.

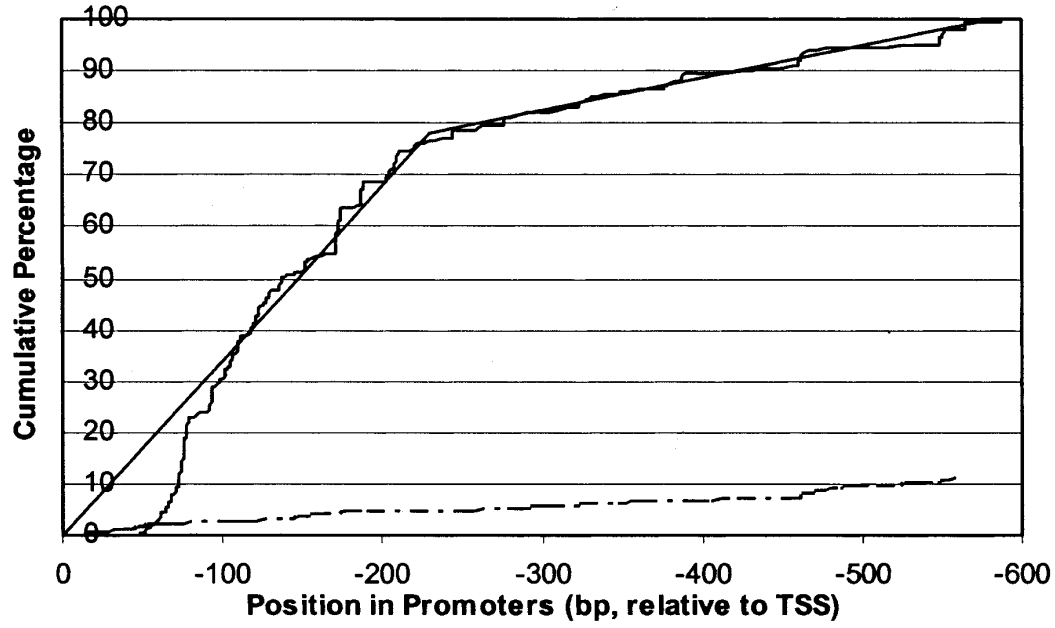

Figure 1 Position distribution of NF-kB binding sites. The $x$-axis is the position of NF- $\mathrm{kB}$ binding sites relative to the transcription start site. The $y$-axis is the cumulative percentage of NF- $\mathrm{kB}$ binding sites. The upper (solid) curve is for NF- $\mathrm{kB}$ sites in immune promoters, and the lower (dotted) curve is for NF- $\mathrm{KB}$ sites in nonimmune promoters (percentage relative to total NF- $\mathrm{kB}$ binding sites in the 62 immune promoters). The upper curve has roughly two phases; one is between -1 and $-230 \mathrm{bp}$, and the other is from -231 to $-600 \mathrm{bp}$. The turning point is revealed by piecewise linear regression (solid lines). Over $75 \%$ of NF-KB sites are within the 230-bp region immediately upstream of TSS. From the dotted curve, it appears that NF-KB sites in nonimmune promoters do not have positional preference.

\section{Searching for NF-кB-Regulated Immune Genes}

Our algorithm for finding NF-кB-regulated immune gene promoters is shown in Figure 3 . For each promoter, we first check for an $\mathrm{NF}-\kappa \mathrm{B}$ binding site in the first $600 \mathrm{bp}$ upstream of the TSS. If none is found, we exit the algorithm. If an NF-кB binding site is found and it is in the -1 to $-230 \mathrm{bp}$ window we use model I; otherwise we use model II. If a promoter has a pattern of TF binding sites yielding a probability, $\pi(x)$ (probability of being from the immune gene group), which exceeds the threshold established for the LRA model used, we consider the promoter a preliminary candidate.

To increase the specificity of our predictions, we compared the preliminary candidates with their mouse or fly homologs. If possible, they were checked for conserved $\mathrm{NF}-\kappa \mathrm{B}$ binding sites in the mouse genome, but we do not have genomic sequences for all mouse genes. In such cases, we compared the preliminary candidates with the Drosophila genome. Although flies have only a simple form of immune response (innate immu- 


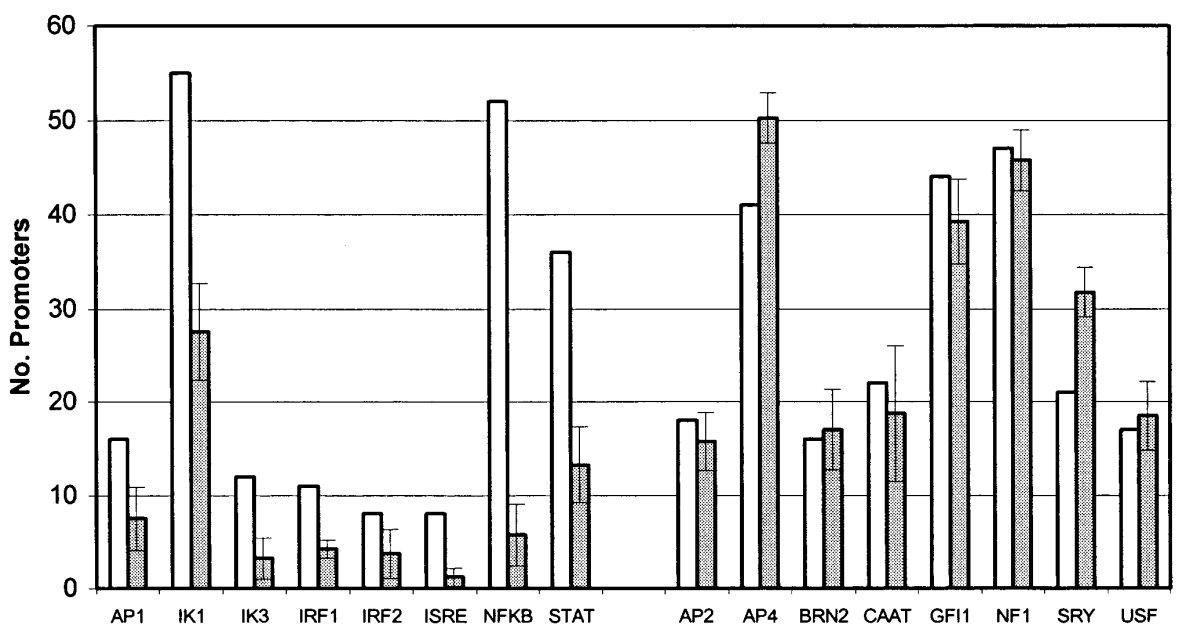

Figure 2 Abundance of transcription factor binding sites. Comparisons are made between the 62 NF-кB-regulated promoters and four sets of 62 mammalian nonimmune promoters from the EPD. The $y$-axis is the number of promoters with at least one binding site for the transcription factor. The white bar is the number of NF-кB-regulated immune gene promoters with the TF, and the gray bar is the mean count of promoters with the TF in the four sets of nonimmune promoters. The error bars represent one standard deviation in the nonimmune promoter data. Note that among the $62 \mathrm{NF}-\kappa \mathrm{B}-$ regulated promoters, the number of promoters with NF-kB sites is 53 , instead of 62 . In this analysis, we set a high PWM threshold for detecting NF- $\mathrm{BB}$ binding sites (0.9), and thus we did not detect variant sites.

nity), conservation of regulatory regions across such evolutionary distance is likely to be functionally important. On searching the 62 known NF-кB-regulated immune genes, our method selected 18 promoters by model I and eight promoters by model II, yielding sensitivity of $26 / 62$, or $42 \%$.

Next, we searched for NF-кB-regulated immune gene promoters among the 6440 human promoters previously identified by CONPRO (Liu and States 2002). CONPRO finds promoters that are associated with mRNA transcripts, and thus finding an immune promoter is equivalent to finding an immune gene. Among the 6440 promoters, we found $28 \mathrm{im}-$ mune genes, 22 genes by model I and six genes by model II.

\section{Specificity: Predicted Immune Genes With Known Function}

Among the 22 predicted immune gene promoters found by model I, 15 regulate well characterized human genes (Table
2). Eleven of these promoters have been cloned, and mutagenesis studies confirmed that the genes are NF- $\mathrm{B}$-regulated (Promoter Study, Table 2). Two other genes, $M A P 3 K 8$ and $M I P-3 \alpha$, have gene expression data consistent with NF$\kappa \mathrm{B}$ regulation (Gene; Array; Table 2): MAP3K8 is regulated by activation of NF- $\mathrm{KB}$ under five different experimental conditions, and MIP$3 \alpha$ shows increased expression after $\mathrm{NF}-\kappa \mathrm{B}$ is activated by seven different stimulators in different cell lines.

Inositol 1,4,5-triphosphate kinase C (IP3KC) was cloned (Dewaste et al. 2000), but data from expression studies are not yet available. However, the IP3 second messenger signaling pathway is involved in T-cell and B-cell activation and differentiation, as well as in monocyte and macrophage signaling. There are three IP3 kinase isoforms, IP3KA, IP3KB, and IP3KC. It was initially observed that the IP3 kinase in thymus and lymphocytes has a higher molecular weight than IP3KA and IP3KB (D'Santos et al. 1994). It was later shown that the IP3 kinase in thymus is isoform C (Dewaste et al. 2000). Furthermore, the IP3KC promoter has binding sites for IK1, AP1, STAT, and $\mathrm{NF}-\kappa \mathrm{B}$; , whereas the IP3KB and IP3KA promoters do not have any of the above sites. Based on these studies, we believe that IP3KC is the isoform expressed in the immune system, regulating T-cell and B-cell activation. Model I also predicts $p 84$ as an immune gene, but we found no experimental evidence to confirm this, yielding specificity of $14 / 15$, or $93 \%$ for model I.

Model II predicts six immune gene promoters, with four of them regulating well characterized genes (Table 3). The first three of these genes have been shown in promoter studies to have immune functions and NF- $\mathrm{B}$ regulation. Additionally, MyD118 (gadd45beta) is a response gene in myeloid differentiation and is upregulated when NF- $\mathrm{BB}$ is activated in both $\mathrm{T}$ and $\mathrm{B}$ cells. Ecto-ATPase provides signals for activating cyto-

Table 1. The LRA Models for NF-кB-Regulated Immune Gene Promoters

\begin{tabular}{|c|c|c|c|c|c|c|c|}
\hline \multirow[b]{2}{*}{ LRA model } & \multirow{2}{*}{$\begin{array}{c}\text { Model } \\
\text { variables }\end{array}$} & \multicolumn{3}{|c|}{$\begin{array}{l}\text { Promoters with NF-kB } \\
\text { sites from }-1 \text { to }-230 \mathrm{bp}\end{array}$} & \multicolumn{3}{|c|}{$\begin{array}{l}\text { Promoters with NF-kB } \\
\text { sites only from }-231 \text { to }-600 b p\end{array}$} \\
\hline & & Coeff. & S.E. & P-value & Coeff. & S.E. & P-value \\
\hline \multirow{6}{*}{$\begin{array}{l}\text { Model w/o number of } \\
\text { TF binding sites }\end{array}$} & Intercept & -3.45 & 0.38 & $6.1 \mathrm{E}-17$ & -5.80 & 0.98 & $8.8 \mathrm{E}-09$ \\
\hline & NF-кB & 3.49 & 0.44 & 4.3E-14 & 4.19 & 0.95 & $1.5 \mathrm{E}-05$ \\
\hline & AP1 & 0.70 & 0.47 & 0.135 & 1.35 & 0.96 & 0.160 \\
\hline & IK & 0.87 & 0.49 & 0.074 & 1.73 & 0.81 & 0.034 \\
\hline & IRF & 0.93 & 0.64 & 0.146 & 2.67 & 0.91 & 0.003 \\
\hline & STAT & 1.00 & 0.44 & 0.022 & 0.70 & 0.75 & 0.355 \\
\hline
\end{tabular}

The columns labeled Coeff. are the coefficients in the logistic regression model. S.E. is the standard error in the fit for the coefficient, and P-value is the probability of observing a coefficient this far from 0 in a fit to random data. The weight matrix score cutoff for NF-KB and AP1 sites is 0.95; that for the IK1, IK3 binding sites is 0.94; for STAT, IRF1, IRF2, and ISRE, the score cutoff is 0.91 . 


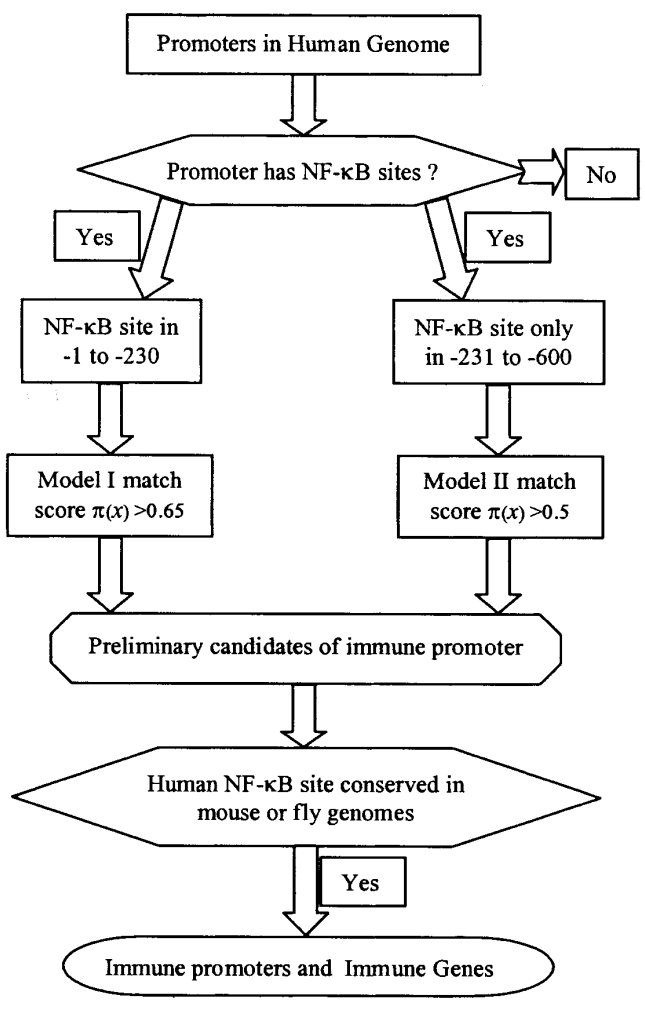

Figure 3 Algorithm for searching for immune genes. The promoters with NF-KB binding sites are checked for positions of the binding sites. Model I or model II is used to estimate the probability that a promoter fits in the group of immune promoters. The last step of the procedure is verification of NF- $\mathrm{kB}$ binding site conservation in the mouse or fly genome. The promoters found by this method are predictions of immune gene promoters.

kine secretion in T cells and antibody secretion in B cells, as well as signals for B-cell proliferation. As such, all four of the model II predictions are supported by experimental data, yielding specificity of $4 / 4$, or $100 \%$.

\section{Novel Predictions of NF-кB-Regulated Immune Genes}

Our method predicts nine novel immune genes (Table 4). Although these genes are not well characterized, there is some evidence to support immune function in these genes. Two of these nine genes have well studied homologs in model organisms. The first one is AJ245599, and the Drosophila homolog is four-jointed ( $f j)$, which is a putative intercellular signaling protein (Brodsky and Steller 1996). It has also been shown that $f j$ may be a downstream gene in the JAK/STAT pathway in Drosophila (Zeidler et al. 2000). The role of the JAK/STAT pathway in the immune system is well established (Leonard and O'Shea 1998), so we have reason to believe that AJ245599 encodes an immune-related gene in humans. Another gene having characterized homologs is $A K 025876$ (sir2 homolog 2), which is one of seven human sir2 homologs. The yeast sir2 homolog is a histone deacetylase, which causes gene silencing and is related to aging (Shore 2000). However, in humans the protein product of $A K 025876$ primarily locates in the cytoplasm, rather than the nucleus, and overexpression of the gene in human cells has no effects on cell growth or chromosome stability (Afshar and Murnane 1999). These experiments suggest that the human homolog has functions that are dif- ferent from yeast sir2 unrelated to gene silencing and aging, and we propose that the human gene functions in the immune system.

SAGE data on monocytes and T cells recently became available (Hashimoto et al. 1999; Suzuki et al. 2000; Nagai et al. 2001; Shires et al. 2001), and a SAGE study was performed on human microvascular endothelial cells (HMVEC; G.J. Reggins). Changes in the expression levels of these nine genes after the activation of NF- $\mathrm{KB}$ in these cell lines, along with estimates of the statistical significance ( $P$-values) of these changes are summarized in the last column of Table 4 (Audic and Claverie 1997). The activators of NF-кB include LPS, MCSF, or GM-CSF on monocytes; phorbol myristate acetate (PMA) on T cells; and vascular endothelial growth factor (VEGF) on HMVEC (Kim et al. 2001). In these cell lines, after activation of NF-кB we observe that the expression level of these nine genes increases significantly, and thus SAGE data are consistent with the prediction that these novel genes are regulated by NF-кB. Given the evidence that our method is very specific, we are convinced that these nine genes are novel NF-кB-regulated immune response genes.

\section{DISCUSSION}

Given the fundamental roles of the NF- $\mathrm{B}$ signaling pathway in the immune system, identifying novel NF-кB-regulated immune genes in the human genome will undoubtedly advance the investigation of immune mechanisms. Although experimental methods such as DNA microarrays are available to characterize patterns of gene expression, these methods are expensive and require biological materials which may be difficult to obtain for some tissues and conditions. Thus, computational methods can complement experimental methods by identifying candidate genes, maximizing the effectiveness of expression studies. We build LRA models for immune promoters with NF- $\mathrm{B}$ binding sites within the -1 to -230 -bp window (model I), and for promoters with NF- $\mathrm{B}$ binding sites between -231 and -600 bp (model II). This method shows sensitivity of $42 \%$, with specificity of $93 \%-100 \%$.

We found 28 immune gene promoters with an LRA model score above the threshold and with NF-кB binding sites conserved in the mouse or Drosophila genome. These 28 genes are predicted to be immune response genes, with nine genes among them being novel NF-кB-regulated immune genes. For all of the nine predicted novel immune genes, SAGE data on microvascular endothelial, myeloid, or lymphoid cells suggest that they are NF-кB-regulated genes. Because our search procedure is very specific, we propose that these nine genes are NF-кB-regulated immune response genes.

One of these novel NF-кB-regulated immune genes (sir2 homolog 2) is notable. The yeast sir2 protein is believed to be functional in the nucleus and is involved in gene silencing and aging (Shore 2000). However, the human homolog 2 primarily locates in cytoplasm, and overexpression of the gene has no affect on cell growth or chromosome stability (Afshar and Murnane 1999). Our LRA analysis suggests that it is an immune gene in humans, and SAGE data further demonstrate that the gene is expressed in both lymphoid and myeloid lineages after the cells are stimulated by NF-кB activators. We anticipate that the gene plays a fundamental role which is common to both lymphoid and myeloid cells.

The score thresholds $(\pi[x])$ for the two models are set so that for model I $(\pi[x]>0.65)$, the promoter must have binding sites for NF- $\mathrm{B}$, and at least one other informative TF (AP1, 
Liu et al.

Table 2. Model 1 Predictions of Immune Genes Among Well Characterized Genes

\begin{tabular}{|c|c|c|c|c|c|}
\hline Gene name & Acc. no. & $\begin{array}{l}\text { Evidence of } \\
\text { NF-kB } \\
\text { regulation }\end{array}$ & $\begin{array}{l}\text { Immune } \\
\text { gene }\end{array}$ & $\begin{array}{l}\text { Model } \\
\text { score }\end{array}$ & Functions in immune system \\
\hline RANTES & AF088219 & Promoter study ${ }^{(1)}$ & $+^{(2)}$ & 0.935 & Activator of variety of leukocytes \\
\hline ELAM-1 & AL021940 & Promoter study ${ }^{(3)}$ & $+(4)$ & 0.833 & Migration of leukocytes \\
\hline$H L A-B$ & AJ250917 & Promoter study(5) & + & 0.935 & MHC class I molecule \\
\hline IL8 & M26383 & Promoter study ${ }^{(3)}$ & $++^{(6)}$ & 0.850 & Acute inflammation \\
\hline GROy & M36821 & Promoter study ${ }^{(3)}$ & $+{ }^{(7)}$ & 0.850 & Macrophage inflammatory protein \\
\hline CD83 & NM_004233 & Promoter study ${ }^{(8)}$ & $+\left({ }^{(9)}\right.$ & 0.833 & Dendritic cells maturation \\
\hline$N F-\kappa B 2$ & S76638 & Promoter study ${ }^{(3)}$ & $++^{(3)}$ & 0.739 & Regulator of immune response \\
\hline MAJCAM1 & U43628 & Promoter study ${ }^{(3)}$ & $+(10)$ & 0.714 & Migration of leukocytes \\
\hline IL6 & X04430 & Promoter study ${ }^{(3)}$ & $+(11)$ & 0.677 & Acute immune response \\
\hline TNF- $\beta$ & D12614 & Promoter study ${ }^{(3)}$ & $t^{(12)}$ & 0.739 & Lymphoid organ development and chronic inflammation \\
\hline CD69 & Z22576 & Promoter study ${ }^{(3)}$ & $+(13)$ & 0.871 & $\begin{array}{l}\text { T-cell activation and function in other hematopoietic lineage } \\
\text { cells }\end{array}$ \\
\hline МАРЗК8 & D14497 & Gene ${ }^{(14)}$ & $+(15)$ & 0.739 & Regulator of NF-кB in T cells; Involved in T-cell activation \\
\hline$M I P-3 \alpha$ & U64197 & Gene $^{(16)} ; \operatorname{array}^{(17)}$ & + & 0.714 & Macrophage inflammatory protein \\
\hline$I P 3 K C$ & D38169a & $\mathrm{N} / \mathrm{A}$ & $++^{(18)}$ & 0.714 & $\begin{array}{l}\text { T/B cell activation/differentiation; Signaling in monocyte/ } \\
\text { macrophage }\end{array}$ \\
\hline Nuclear matrix p84 & L36529 & N/A & - & 0.850 & N/A \\
\hline
\end{tabular}

${ }^{a} \mathrm{NF}-\kappa \mathrm{B}$ binding site conserved in Drosophila, otherwise conserved in the mouse genome.

In the third column, experimental evidence on whether the promoters are regulated by NF-кB is found in the literature. "Promoter study" means the promoters have been cloned upstream of a reporter gene and expression assays demonstrated that the promoters are regulated by NF-кB. "Gene" means that a single gene expression assay of the candidate, usually by Northern blot, shows increased expression in cells after activating NF- $\mathrm{KB}$ with the stimulating factors. "Array" refers to microarray experiments showing that expression of the gene increases after $\mathrm{NF}-\kappa \mathrm{B}$ is activated in the cells. In the fourth column, a plus sign means the genes play a role in the immune system. The fifth column gives the score $(\pi[x])$ for the promoter in the LRA model. Ref. (1) Lee et al. 2000; Moriuchi et al. 1997. (2) Appay and Rowland-Jones 2001. (3) Baeuerle and Baichwal 1997. (4) Elangbam et al. 1997. (5) Girdlestone 2000; Gobin et al. 1998. (6) Harada et al. 1994. (7) Driscoll 1994. (8) McKinsey et al. 2000. (9) Robinson et al. 1998. (10) Elangbam et al. 1997. (11) Tilg et al. 1997; Akira and Kishimoto 1992. (12) Ruddle 1999. (13) Marzio et al. 1999; Ziegler et al. 1994. (14) Expression data in fibroblasts: OA, IL-1 (Chan et al. 1993); Spleen cells: Con A (Patriotis et al. 1993); T: $\alpha C D 3$, phorbol ester (Sanchez-Gongora et al. 2000). (15) Belich et al. 1999; Patriotis et al. 1993. (16) Expression data in THP-1:PMA; PBMC:LPS; I-HUVEC:TNF $\alpha$ (Hromas et al. 1997); Macrophage: Influenza A, Sendai virus (Matikainen et al. 2000). (17) Expression data in THP1:L. monocytogenes (Cohen et al. 2000); Macrophages:LDL (Shiffman et al. 2000). (18) Marshall et al. 2000; Chow et al. 1995; Ward and Cantrell 2001.

IK, IRF, or STAT) to be considered a preliminary candidate. To meet the threshold for model II $(\pi[x]>0.50)$, the promoter must have binding sites for NF- $\mathrm{B}$ and either IK or IRF, else NF-kB and both AP1 and STAT.

Because our goal is to develop a specific method for immune gene prediction, we set the position weight matrix (PWM) thresholds high to reduce false predictions. The high specificities of model I (93\%) and model II (100\%) tend to justify expensive and time-consuming experimental characterization of the nine predicted immune genes. Because the sensitivity of our method is $42 \%$ and we have 28 predictions from 6440 genes, we would expect that there are about 70 NF-кB-regulated immune genes among the 6440 genes and about 400 NF-кB-regulated immune genes among the 35,000 genes in the entire human genome.

This is the first successful attempt at a genome-scale computational search for immune genes by promoter analysis. As the sequencing of the human genome is finished, assigning functions to novel genes in a high-throughput manner becomes increasingly important. We demonstrate here that regulatory genomics can be applied to genome-scale prediction of the functions for novel genes in specific physiological pathways or biological systems.

\section{METHODS}

\section{Promoters and TF Binding Sites}

Transcription factor binding sites are analyzed by MatInspector (Quandt et al. 1995). The weight matrices for transcription factor binding sites are from TRANSFAC (Wingender et al. 2000), and the weight matrix score cutoffs are 0.95 for AP1 and 0.9 for other transcription factors, unless otherwise specified in the text.

\section{Piecewise Linear Regression}

Piecewise linear regression analysis (S-Plus6.0) was used to reveal the turning point in the NF- $\mathrm{B}$ binding-site positional distribution curve (Fig. 1). In a two-segment curve, piecewise linear regression analysis fits both sections with lines after a knot is specified. We choose the knot yielding the minimal sum of squared errors $(-270 \mathrm{bp})$.

\section{Logistic Regression Analysis}

We also used S-Plus6.0 to perform a multivariate logistic regression analysis (LRA). In the LRA, maximum likelihood was used to estimate the relative effect of each TF binding site on the probability that a promoter is associated with an immune gene. We first tested for possible synergistic effects of multiple-copy TF binding by fitting two linear models: One model uses the count of binding sites for each TF in each promoter, and the other model uses an indicator variable for the existence of at least one binding site for each TF in a promoter, regardless of the TF copy number. The count of TFs was not found to be significant, so we used indicator variables for the presence of binding sites for AP1, IK (IK1, IK3), IRF (IRF1, IRF2, ISRE), NF- $\kappa$ B, or STAT. Modeling was performed on the 62 NF-кB-regulated immune promoters and the 248 mammalian nonimmune promoters extracted from the EPD. The probability that a given promoter is from the group of immune genes, $\pi(x)$, is estimated by: 
Table 5. Effects of Stringency of TF Sites on Specificity

\begin{tabular}{lccc}
\hline Stringency & Sensitivity & Model 1 & Model 2 \\
\hline High & $42 \%$ & $14 / 15$ & $4 / 4$ \\
Medium & $61 \%$ & $2 / 5$ & $2 / 5$ \\
Low & $71 \%$ & $0 / 7$ & $1 / 10$ \\
\hline
\end{tabular}

High stringency is the original model I and II, as in the above analyses. In medium stringency, we lower the matrix cutoff scores to NF-кB, 0.95; AP1, 0.95; IK1, 0.94; STAT, 0.91; IK3, IRF1, IRF2, ISRE, 0.86. Low stringency sets the matrix cutoff scores to NF-KB, 0.92; AP1, 0.95; IK1, 0.94; STAT, 0.91; IK3, IRF1, IRF2, ISRE, 0.86 . As we lower the matrix cutoffs, only the additional predictions are shown in the table.

specificity is very high (18/19 overall) using our high threshold for accepting TF binding sites, but sensitivity is only $42 \%$ $(26 / 62)$. With medium stringency (described in Table 5), the sensitivity increases to $61 \%$, but the specificity among these additional predictions drops to $40 \%$ (4/10 additional predictions with known function being NF-кB-regulated immune genes). Lowering the stringency further brings the specificity down dramatically, because only one of the 17 additional predicted genes with known functions is likely to be an immune gene, and the sensitivity is only slightly improved (71\%). We conclude that the high stringency search has detected most of the immune genes which could be detected by this method and should be applied when we take a genomic approach to search for genes with specific functions.

\section{ACKNOWLEDGMENTS}

We thank Tom Blackwell and the rest of the group for insightful discussions, and the reviewers for their constructive comments. This work was supported in part through grants from the NIH (HG-R01-01391), the Department of Energy (DEFG02-94ER61910), and the Merck Foundation for Genome Research (grant \#225)

The publication costs of this article were defrayed in part by payment of page charges. This article must therefore be hereby marked "advertisement" in accordance with 18 USC section 1734 solely to indicate this fact.

\section{REFERENCES}

Afshar, G. and Murnane, J.P. 1999. Characterization of a human gene with sequence homology to Saccharomyces cerevisiae SIR2. Gene 234: 161-168.

Akira, S. and Kishimoto, T. 1992. IL-6 and NF-IL6 in acute-phase response and viral infection. Immunol. Rev. 127: 25-50.

Appay, V. and Rowland-Jones, S.L. 2001. RANTES: A versatile and controversial chemokine. Trends Immunol. 22: 83-87.

Audic, S. and Claverie, J.M. 1997. The significance of digital gene expression profiles. Genome Res. 7: 986-995.

Baeuerle, P.A. and Baichwal, V.R. 1997. NF-к B as a frequent target for immunosuppressive and anti-inflammatory molecules. $A d v$. Immunol. 65: 111-137.

Baeuerle, P.A. and Baltimore, D. 1996. NF-к B: Ten years after. Cell 87: 13-20.

Belich, M.P., Salmeron, A., Johnston, L.H., and Ley, S.C. 1999. Tpl-2 kinase regulates the proteolysis of the NF-кB-inhibitory protein NF-кB1 p105. Nature 397: 363-368.

Berman, B.P., Nibu, Y., Pfeiffer, B.D., Tomancak, P., Celniker, S.E., Levine, M., Rubin, G.M., and Eisen, M.B. 2002. Exploiting transcription factor binding site clustering to identify cis-regulatory modules involved in pattern formation in the Drosophila genome. Proc. Natl. Acad. Sci. 99: 757-762.

Brodsky, M.H. and Steller, H. 1996. Positional information along the dorsal-ventral axis of the Drosophila eye: Graded expression of the four-jointed gene. Dev. Biol. 173: 428-446.

Campbell, R.D., Carroll, M.C., and Porter, R.R. 1986. The molecular genetics of components of complement. Adv. Immunol.
38: $203-244$

Chan, A.M., Chedid, M., McGovern, E.S., Popescu, N.C., Miki, T., and Aaronson, S.A. 1993. Expression cDNA cloning of a serine kinase transforming gene. Oncogene 8: 1329-1333.

Chow, C.W., Grinstein, S., and Rotstein, O.D. 1995. Signaling events in monocytes and macrophages. New Horiz. 3: 342-351.

Cohen, P., Bouaboula, M., Bellis, M., Baron, V., Jbilo, O., Poinot-Chazel, C., Galiegue, S., Hadibi, E.H., and Casellas, P. 2000. Monitoring cellular responses to Listeria monocytogenes with oligonucleotide arrays. J. Mol. Biol. 275: 11181-11190.

De Smaele, E., Zazzeroni, F., Papa, S., Nguyen, D.U., Jin, R., Jones, J., Cong, R., and Franzoso, G. 2001. Induction of gadd $45 \beta$ by NF- $\mathrm{B}$ downregulates proapoptotic JNK signalling. Nature 414: 308-313.

Dewaste, V., Pouillon, V., Moreau, C., Shears, S., Takazawa, K., and Erneux, C. 2000. Cloning and expression of a cDNA encoding human inositol 1,4,5-trisphosphate 3-kinase C. Biochem. J. 352: 343-351.

Dombrowski, K.E., Ke, Y., Brewer, K.A., and Kapp, J.A. 1998. Ecto-ATPase: An activation marker necessary for effector cell function. Immunol. Rev. 161: 111-118.

Driscoll, K.E. 1994. Macrophage inflammatory proteins: Biology and role in pulmonary inflammation. Exp. Lung. Res. 20: 473-490.

D'Santos, C.S., Communi, D., Ludgate, M., Vanweyenberg, V., Takazawa, K., and Erneux, C. 1994. Identification of high molecular weight forms of inositol 1,4,5-trisphosphate 3-kinase in rat thymus and human lymphocytes. Cell. Signal. 6: 335-344.

Elangbam, C.S., Qualls, C.W.J., and Dahlgren, R.R. 1997. Cell adhesion molecules-Update. Vet. Pathol. 34: 61-73.

Fambrough, D., McClure, K., Kazlauskas, A., and Lander, E.S. 1999. Diverse signaling pathways activated by growth factor receptors induce broadly overlapping, rather than independent, sets of genes. Cell 97: 727-741.

Gao, L., Dong, L., and Whitlock Jr., J.P., 1998. A novel response to dioxin. Induction of ecto-ATPase gene expression. J. Biol. Chem. 273: $15358-15365$.

Ghosh, S., May, M.J., and Kopp, E.B. 1998. NF-к B and Rel proteins: Evolutionarily conserved mediators of immune responses. Annu. Rev. Immunol. 16: 225-260.

Girdlestone, J. 2000. Synergistic induction of HLA class I expression by RelA and CIITA. Blood 95: 3804-3808.

Gobin, S.J., Keijsers, V., van Zutphen, M., and van den Elsen, P.J. 1998. The role of enhancer A in the locus-specific transactivation of classical and nonclassical HLA class I genes by nuclear factor кB. J. Immunol. 161: 2276-2283.

Hamilton, J.A. 1997. CSF-1 signal transduction. J. Leukoc. Biol. 62: $145-155$

Harada, A., Sekido, N., Akahoshi, T., Wada, T., Mukaida, N., and Matsushima, K. 1994. Essential involvement of interleukin-8 (IL-8) in acute inflammation. J. Leukoc. Biol. 56: 559-564.

Hashimoto, S., Suzuki, T., Dong, H.Y., Yamazaki, N., and Matsushima, K. 1999. Serial analysis of gene expression in human monocytes and macrophages. Blood 94: 837-844.

Hromas, R., Gray, P.W., Chantry, D., Godiska, R., Krathwohl, M., Fife, K., Bell, G.I., Takeda, J., Aronica, S., Gordon, M., et al. 1997. Cloning and characterization of exodus, a novel $\beta$-chemokine. Blood 89: 3315-3322.

International Human Genome Sequencing Consortium. 2001. Initial sequencing and analysis of the human genome. Nature 409: 860-921.

Kadonaga, J.T. 1998. Eukaryotic transcription: An interlaced network of transcription factors and chromatin-modifying machines. Cell 92: 307-313.

Kas-Deelen, A.M., Bakker, W.W., Olinga, P., Visser, J., de Maar, E.F., van Son, W.J., The, T.H., and Harmsen, M.C. 2001. Cytomegalovirus infection increases the expression and activity of ecto-ATPase (CD39) and ecto-5'nucleotidase (CD73) on endothelial cells. FEBS Lett. 491: 21-25.

Kim, I., Moon, S.O., Kim, S.H., Kim, H.J., Koh, Y.S., and Koh, G.Y. 2001. Vascular endothelial growth factor expression of intercellular adhesion molecule 1 (ICAM-1), vascular cell adhesion molecule 1 (VCAM-1), and E-selectin through nuclear factor- $\kappa$ B activation in endothelial cells. J. Biol. Chem. 276: 7614-7620.

Krivan, W. and Wasserman, W.W. 2001. A predictive model for regulatory sequences directing liver-specific transcription. Genome Res. 278: 167-181

Lash, A.E., Tolstoshev, C.M., Wagner, L., Schuler, G.D., Strausberg, R.L., Riggins, G.J., Altschul, S.F. 2000. SAGEmap: A public gene expression resource. Genome Res. 10: 1051-1060.

Lee, A.H., Hong, J.H., and Seo, Y.S. 2000. Tumor necrosis factor- $\alpha$ 
and interferon- $\gamma$ synergistically activate the RANTES promoter through nuclear factor $\kappa \mathrm{B}$ and interferon regulatory factor 1 (IRF-1) transcription factors. Biochem. J. 350: 131-138.

Lemon, B. and Tjian, R. 2000. Orchestrated response: A symphony of transcription factors for gene control. Genes \& Dev. 14: $2551-2569$

Leonard, W.J. and O'Shea, J.J. 1998. Jaks and STATs: Biological implications. Annu. Rev. Immunol. 16: 293-322.

Li, J., Peet, G.W., Balzarano, D., Li, X., Massa, P., Barton, R.W., and Marcu, K.B. 2001. Novel NEMO/ІкB kinase and NF-к B target genes at the pre-B to immature B cell transition. J. Biol. Chem. 276: $18579-18590$.

Liu, R. and States, D.J. 2002. Consensus promoter identification in the human genome utilizing expressed gene markers and gene modeling. Genome Res. 12: 462-469

Liu, R., Blackwell, T.W., and States, D.J. 2001. Conformational models for binding site recognition by the $E$. coli MetJ transcription factor. Bioinformatics 17: 622-633.

Markstein, M., Markstein, P., Markstein, V., and Levine, M.S. 2002 Genome-wide analysis of clustered Dorsal binding sites identifies putative target genes in the Drosophila embryo. Proc. Natl. Acad. Sci. 99: 763-768.

Marshall, A.J., Niiro, H., Yun, T.J., and Clark, E.A. 2000. Regulation of B-cell activation and differentiation by the phosphatidylinositol 3-kinase and phospholipase $\mathrm{C} \gamma$ pathway. Immunol. Rev. 76: 30-46.

Marzio, R., Mauel, J., and Betz-Corradin, S. 1999. CD69 and regulation of the immune function. Immunopharmacol. Immunotoxicol. 21: 565-582.

Matikainen, S., Pirhonen, J., Miettinen, M., Lehtonen, A., Govenius-Vintola, C., Sareneva, T., and Julkunen, I. 2000. Influenza A and sendai viruses induce differential chemokine gene expression and transcription factor activation in human macrophages. Virology 276: 138-147.

McKinsey, T.A., Chu, Z., Tedder, T.F., and Ballard, D.W. 2000. Transcription factor NF-кB regulates inducible CD83 gene expression in activated T lymphocytes. Mol. Immunol. 37: 783-788.

Moriuchi, H., Moriuchi, M., and Fauci, A.S. 1997. Nuclear factor-к B potently upregulates the promoter activity of RANTES, a chemokine that blocks HIV infection. J. Immunol. 158: $3483-3491$.

Nagai, S., Hashimoto, S., Yamashita, T., Toyoda, N., Satoh, T., Suzuki, T., and Matsushima, K. 2001. Comprehensive gene expression profile of human activated $\mathrm{T}(\mathrm{h}) 1$ - and $\mathrm{T}(\mathrm{h}) 2$-polarized cells. Int. Immunol. 13: 367-376.

Patriotis, C., Makris, A., Bear, S.E., and Tsichlis, P.N. 1993. Tumor progression locus 2 (Tpl-2) encodes a protein kinase involved in the progression of rodent T-cell lymphomas and in T-cell activation. Proc. Natl. Acad. Sci. 90: 2251-2255.

Perier, R.C., Praz, V., Junier, T., Bonnard, C., and Bucher, P. 2000. The eukaryotic promoter database. Nucleic Acids Res. 28: 302-303.

Quandt, K., Frech, K., Karas, H., Wingender, E., and Werner, T 1995. MatInd and MatInspector: New fast and versatile tools for detection of consensus matches in nucleotide sequence data. Nucleic Acids Res. 23: 4878-4884.

Robinson, S.P., Saraya, K., and Reid, C.D. 1998. Developmental aspects of dendritic cells in vitro and in vivo. Leuk. Lymphoma 29: $477-490$

Ruddle, N.H. 1999. Lymphoid neo-organogenesis: Lymphotoxin's role in inflammation and development. Immunol. Res. 19: $119-125$

Sanchez-Gongora, E., Lisbona, C., de Gregorio, R., Ballester, A., Calvo, V., Perez-Jurado, L., and Alemany, S. 2000. COT kinase proto-oncogene expression in T cells: Implication of the JNK/SAPK signal transduction pathway in COT promoter activation. J. Biol. Chem. 275: 31379-31386.

Shiffman, D., Mikita, T., Tai, J.T., Wade, D.P., Porter, J.G., Seilhamer, J.J., Somogyi, R., Liang, S., and Lawn, R.M. 2000. Large scale gene expression analysis of cholesterol-loaded macrophages. $J$. Biol. Chem. 275: 37324-37332.

Shires, J., Theodoridis, E., and Hayday, A.C. 2001. Biological insights into TCR $\gamma \delta+$ and TCR $\alpha \beta+$ intraepithelial lymphocytes provided by serial analysis of gene expression (SAGE). Immunity 15: $419-434$.

Shore, D. 2000. The Sir2 protein family: A novel deacetylase for gene silencing and more. Proc. Natl. Acad. Sci. 97: 14030-14032.

Suzuki, T., Hashimoto, S., Toyoda, N., Nagai, S., Yamazaki, N., Dong, H.Y., Sakai, J., Yamashita, T., Nukiwa, T. and Matsushima, K. 2000. Comprehensive gene expression profile of LPS-stimulated human monocytes by SAGE. Blood 96: 2584-2591.

Thanos, D. and Maniatis, T. 1995. NF-к B: A lesson in family values. Cell 80: 529-532.

Tilg, H., Dinarello, C.A., and Mier, J.W. 1997. IL-6 and APPs: Anti-inflammatory and immunosuppressive mediators. Immunol. Today 18: 428-432.

Vairapandi, M., Balliet, A.G., Fornace Jr., A.J., Hoffman, B., and Liebermann, D.A. 1996. The differentiation primary response gene $M y D 118$, related to GADD45, encodes for a nuclear protein which interacts with PCNA and p21WAF1/CIP1. Oncogene 12: $2579-2594$.

Venter, J.C., Adams, M.D., Myers, E.W., Li, P.W., Mural, R.J., Sutton, G.G., Smith, H.O., Yandell, M., Evans, C.A., Holt, R.A., et al. 2001. The sequence of the human genome. Science 291: $1304-1351$.

Ward, S.G. and Cantrell, D.A. 2001. Phosphoinositide 3-kinase in T lymphocyte activation. Curr. Opin. Immunol. 13: 332-338.

Wasserman, W.W. and Fickett, J.W. 1998. Identification of regulatory regions which confer muscle-specific gene expression. J. Mol. Biol. 278: 167-181.

Wingender, E., Chen, X., Hehl, R., Karas, H., Liebich, I., Matys, V., Meinhardt, T., Pruss, M., Reuter, I., and Schacherer, F. 2000. TRANSFAC: An integrated system for gene expression regulation. Nucleic Acids Res. 28: 316-319.

Yuh, C.H., Bolouri, H., and Davidson, E.H. 1998. Genomic cis-regulatory logic: Experimental and computational analysis of a sea urchin gene. Science 279: 1896-1902.

Zeidler, M.P., Bach, E.A., and Perrimon, N. 2000. The roles of the Drosophila JAK/STAT pathway. Oncogene 19: 2598-2606.

Ziegler, S.F., Ramsdell, F., and Alderson, M.R. 1994. The activation antigen CD69. Stem Cells 12: 456-465.

\section{WEB SITE REFERENCES}

http://genome.ucsc.edu; Golden path genome sequences. www.prevent.m.u-tokyo.ac.jp/SAGE.html; SAGE data. http://www.ncbi.nlm.nih.gov/SAGE; SAGE data.

Received October 15, 2002; accepted in revised form December 12, 2002.
Genome Research www.genome.org 


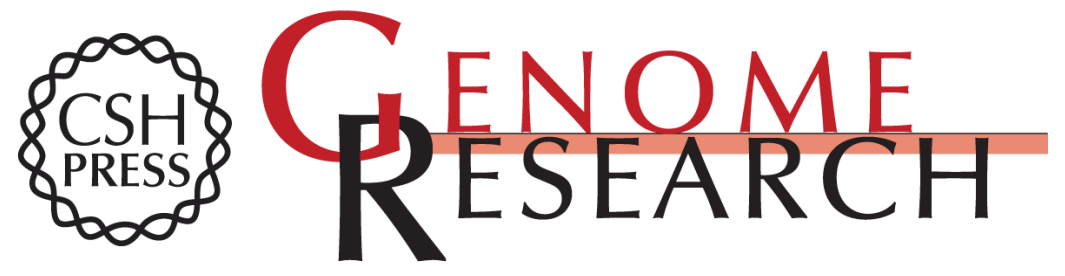

\section{Computationally Identifying Novel NF-кB-Regulated Immune Genes in the Human Genome}

Rongxiang Liu, Richard C. McEachin and David J. States

Genome Res. 2003 13: 654-661

Access the most recent version at doi:10.1101/gr.911803

References This article cites 64 articles, 21 of which can be accessed free at:

http://genome.cshlp.org/content/13/4/654.full.html\#ref-list-1

\section{License}

Email Alerting Receive free email alerts when new articles cite this article - sign up in the box at the Service top right corner of the article or click here.

\section{Affordable, Accurate Sequencing.}

To subscribe to Genome Research go to: https://genome.cshlp.org/subscriptions 